\title{
Effect of Lipid Composition on the Toxicity of Trichlorobenzene Isomers to Diatoms. I. Short-Term Effects of 1,3,5-Trichlorobenzene
}

\author{
Linda Sicko-Goad and Norman A. Andresen \\ Center for Great Lakes and Aquatic Sciences, The University of Michigan, 2200 Bonisteel Blvd, Ann Arbor, Michigan 48109-2099
}

\begin{abstract}
Cultures of Cyclotella meneghiniana and Melosira varians were split into four flasks. Two flasks of each taxon were used for exposure experiments and two were used as controls. Exposure to 1,3,5-trichlorobenzene was initiated in one flask of each taxon in the 11 th hour of the light period on a 16:8 $\mathrm{h} \mathrm{L} / \mathrm{D}$ regime. Another exposure was initiated four hours later in the same day (the 15th hour of the light period) in the second experimental flask of each taxon. These experiments were conducted at $15^{\circ} \mathrm{C}$ and $20^{\circ} \mathrm{C}$ for $2-4$ days and were analyzed for lipid class composition. Cyclotella demonstrated some short-term changes in lipid class composition when exposures were initiated in the 11 th hour of the light cycle at $20^{\circ} \mathrm{C}$ and in both exposures at $15^{\circ} \mathrm{C}$. In contrast, short-term effects were only observed in Melosira when the exposure was initiated in the 11 th hour of the light period at $20^{\circ} \mathrm{C}$. Control cells demonstrated periodicities in lipid composition that appeared to be entrained with the light/dark cycle. The cultures that demonstrated toxicity effects were characterized by low triacylglycerol content, low neutral/polar lipid ratios, and a pattern of chlorophyll synthesis at the time of exposure. It is suggested that rapidly growing cells are more susceptible to short term effects of this trichlorobenzene isomer. Furthermore, timing of the initial exposure may alter toxicity results and this may be a consequence of lipid class composition at the time of exposure.
\end{abstract}

Studies on the diatom Cyclotella meneghiniana (Sicko-Goad et al. 1988, 1989a, 1989b, 1989c, 1989d) demonstrated that lipid content and fatty acid composition varied with time of day when the algae were grown on a 16:8h light/dark cycle. Furthermore, it was observed that the timing of the exposure to chlorinated benzenes altered the expected results. Lipophilicity and chemical reactivity predicted on structure of the compounds had less effect than the time of day the exposure was initiated. We hypothesized that toxicity effects observed might be due to either (1) increased partitioning of the lipophilic toxicant resulting from increased levels of total extractable lipid at certain times of the day or (2) changes in lipid fractions, especially alterations in total polar or total neutral lipids. To test this hypothesis, we conducted two sets of exposure experiments in which diatom cultures were split into separate flasks and exposures to chlorinated benzenes were initiated at two different times of day and at two different temperatures.

\section{Materials and Methods}

\section{Algal Cultures}

Cyclotella meneghiniana Kütz. clone $\mathrm{CyOH} 2$ was obtained from Dr. S. S. Kilham of the Department of Biological Sciences at the University of Michigan. Melosira varians C.A. Ag. was obtained from Dr. H. Vanderploeg of the Great Lakes Environmental Research Lab, NOAA (Ann Arbor, Michigan). Cultures were maintained in WC medium (Guillard 1975) on a rotary shaker table in a growth chamber set at $20^{\circ} \mathrm{C}$ on a $16: 8 \mathrm{~h} \mathrm{light} / \mathrm{dark}$ cycle at $50 \mu \mathrm{ein} / \mathrm{m}^{2} / \mathrm{I}$. For experimental purposes, exponentially growing cells were evenly subdivided among four 2-L extracted and acid washed glass flasks.

Two sets of exposure experiments were conducted. The first experiment was conducted in July 1989 and was an exposure of C. meneghinana and $M$. varians to $0.245 \mathrm{ppm}, 1,3,5$-trichlorobenzene at $20^{\circ} \mathrm{C}$. For this experiment, the trichlorobenzene was made up as a stock solution and methanol was used as a carrier. Stock cultures of each species were evenly divided among four flasks and were diluted with culture medium to a density of approximately 100,000 cells $/ \mathrm{mL}$. Two of the flasks were used as manipulation controls. All samples were withdrawn by a dry air pumping apparatus to minimize loss due to volatilization of toxicant. Controls were sampled similarly. Methanol was added to the control flasks at a concentration of $0.75 \%$, the same concentration in exposure flasks. The 1,3,5-trichlorobenzene isomer was added to one exposure flask at $2 \mathrm{pm}$, which corresponded to the 11 th hour of the light cycle and to the second exposure flask at $6 \mathrm{pm}$, which corresponded to the 15 th hour of the light cycle.

The second exposure experiment was identical in all respects to the first experiment with the exception of temperature, which was $15^{\circ} \mathrm{C}$. Stock cultures for this experiment were acclimated at $15^{\circ} \mathrm{C}$ for two months prior to the exposure.

Aliquots from thoroughly mixed $2-\mathrm{L}$ flasks were withdrawn at times $0,2,24$ and 48 , and for the $15^{\circ} \mathrm{C}$ experiment, $96 \mathrm{~h} .100 \mathrm{~mL}$ were withdrawn per sample. All samples were taken in duplicate, filtered onto prewashed and preweighed Gelman $\mathrm{A} / \mathrm{E}$ glass fiber filters, air dried, then dried in a vacuum oven at $60^{\circ} \mathrm{C}$ for $24 \mathrm{~h}$. Filters were reweighed to determine dry weight and frozen for subsequent lipid extraction.

For lipid analysis, frozen filters were placed in pre-extracted thimbles and extracted with chloroform/methanol $(2: 1 \mathrm{v} / \mathrm{v})$ for at least $12 \mathrm{~h}$ 
Table 1. Standards used for calibration of chromarods

\begin{tabular}{ll}
\hline Lipid class & Standards \\
\hline Aliphatic hydrocarbons & Nonadecane \\
Wax and sterol esters & $\begin{array}{c}\text { Palmitic acid stearyl ester (Stearyl } \\
\text { palmitate) }\end{array}$ \\
Ethyl ketone & 3-Hexadecanone \\
Triacylglycerol & Tripalmitin (Glyceryl tripalmitate) \\
Free fatty acids & Palmitic acid (hexadecanoic acid) \\
Free alcohol & Cetyl alcohol (hexadecanol) \\
Free sterol & Cholesterol (5(6)-cholesten-3-ol) \\
Phospholipids & L- $\alpha$-phosphatidylcholine, \\
& diheptadecanoyl \\
Chlorophyll & Chlorophyll $a$ \\
\hline
\end{tabular}

in a micro-Soxhlet (Orcutt and Patterson 1975). The extract was concentrated, redissolved in chloroform and washed with water in a separatory funnel, dried under a nitrogen stream in a pre-weighed Teflonlined screw cap amber vial and weighed for total gravimetric lipid. Samples were flushed with nitrogen and frozen for lipid class analyses.

Samples were unfrozen and redissolved in methylene chloride to concentrations of $20-50 \mu \mathrm{g}$ lipid in spotting volumes of $10-20 \mu \mathrm{L}$ for lipid class analysis. The extracts were spotted with Hamilton syringes onto cleaned and blank-scanned silica coated chromarods (type SIII). Rods were held in a frame and developed, then scanned in an Iatroscan Mark IV TLC-FID (RSS Inc., Costa Mesa, CA.) system using the development scheme of Parrish (1986). The development was three staged:

1. The rods were developed in $50 \mathrm{~mL}$ solution of hexane, diethyl ether, and formic acid (98:2:0.5) for $30 \mathrm{~min}$, conditioned for $5 \mathrm{~min}$, followed by redevelopment in the same solvent system for $25 \mathrm{~min}$. Rods were then partially scanned for hydrocarbons, wax/sterol esters, and ketones. Wax and sterol esters co-elute in this system while $\beta$-carotene migrates with hydrocarbons.

2. Rods were then reconditioned and developed in $50 \mathrm{~mL}$ of a solution of hexane, diethyl ether and formic acid (80:20:0.1) for $50 \mathrm{~min}$. Rods were scanned for triacylglycerols, free fatty acids, alcohols and sterols. Since triacylglycerols and free fatty acids are difficult to separate if the load on the chromarod is greater than $10 \mu \mathrm{g}$, the area of the split peak has been combined into one class labelled TG/FFA. Diacylglycerols have an Rf value near that of sterols. No diacylglycerol peaks were observed in any samples.

3. The third development consisted of two 15-min developments in $100 \%$ acetone, followed by two 10 -min developments in dichloromethane, methanol and water $(5: 4: 1)$. Rods were then scanned for chlorophyll $a$ (Chl $a$ ), acetone-mobile polar lipids (AMPL), and a class containing phospholipids and acetone-immobile polar lipids. During the last scan, an FTID detector was also used for the additional detection of $\mathrm{N}$ in $\mathrm{Chl} a$ and phospholipids. The AMPL fraction may contain monoglycerides and glycolipids. Chlorophyll data from the TLC-FTID method were compared with standard fluorometric measurements from two experiments. The data were in agreement within one standard error of the TLC-FTID method.

Quantitative determinations of lipid class composition are based on dose-response calibration equations generated by analysis of a wide range of concentrations of standards for each lipid class (Parrish and Ackman 1985). Standards were obtained from Sigma at a purity of $>99 \%$ for lipid class composition studies and are listed in Table 1. All lipid class composition determinations were run in duplicate. Thus, data reported are averages of four replicates for each time determination.

\section{Results}

\section{Cyclotella Lipid Class Composition}

Detailed lipid class composition and selected ratios of lipid classes in Cyclotella demonstrate that lipid class composition of control cultures is considerably different at the two times of day sampled and that temperature may alter lipid class composition. Control data from this experiment and the experiment reported in the following paper were pooled and selected parameters (chlorophyll, triacylglycerols, polar lipid, and the neutral/polar lipid ratio) graphed to determine variation with time. These results are presented in Figure 1 . At $20^{\circ} \mathrm{C}$ control cultures are characterized by a higher chlorophyll content than when cells are maintained at $15^{\circ} \mathrm{C}$. Average neutral/polar lipid ratios are higher at $15^{\circ} \mathrm{C}$. Several fractions of neutral lipids vary considerably with temperature in this diatom. At $20^{\circ} \mathrm{C}$, the predominant neutral lipid class is triacylglycerol, comprising approximately $70 \%$ of the total lipid. At $15^{\circ} \mathrm{C}$, triacylglycerols and a class consisting of wax and sterol esters are both abundant and present in approximately equal proportions.

\section{Melosira Lipid Class Composition}

Variations in chlorophyll, triacylglycerol, polar lipid, and the neutral/polar lipid ratio of Melosira control cells are presented in Figure 2. Like Cyclotella, cultures of Melosira grown at $20^{\circ} \mathrm{C}$ have different lipid profiles when compared with cells cultured at $15^{\circ} \mathrm{C}$. At $20^{\circ} \mathrm{C}$, chlorophyll values are considerably higher. Chlorophyll reaches a peak between the 11th and 13th hours of light at $20^{\circ} \mathrm{C}$ and is also higher in the 11 th hour of light at $15^{\circ} \mathrm{C}$. Neutral to polar lipid ratios rise steadily through the last $8 \mathrm{~h}$ of the light period at $20^{\circ} \mathrm{C}$, and reach a maximum prior to the onset of dark at $15^{\circ} \mathrm{C}$. Cultures maintained at $15^{\circ} \mathrm{C}$, like Cyclotella, have higher percentages of wax/sterol esters. In addition neutral/polar lipid ratios are approximately doubled at this temperature.

\section{Total Extractable Lipid (TEL) as a Function of Light/Dark Cycle}

TEL data from several diel studies as well as values from this paper were pooled and plotted as a function of hour in the $16: 8 \mathrm{~h}$ L/D cycle. These data are presented in Figures 3 and 4 . The diel pattern of TEL in C. meneghiniana (Figure 3) demonstrates that there are cyclical variations in lipid content at $20^{\circ} \mathrm{C}$. Most noticeably, there are peaks in the early (first $8 \mathrm{~h}$ ) and late (second $8 \mathrm{~h}$ ) light periods as well as in the dark period, although the general trend is an increase in the late light and dark periods, with a reduction in total lipid toward the end of the dark period. In contrast, at $15^{\circ} \mathrm{C}$, TEL content is both uniform and low.

The TEL distribution pattern over a diel cycle is quite different in Melosira (Figure 4). TEL content is quite uniform for the first $11 \mathrm{~h}$ of light in Melosira cultured at $20^{\circ} \mathrm{C}$. There is a reduction in the last four hours of the light period, and a bimodal distribution in the dark, which is followed by a return to levels found in the early light period. TEL content is more uniform and slightly lower at $15^{\circ} \mathrm{C}$. 


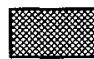

$20^{\circ} \mathrm{C}$

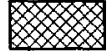

$15^{\circ} \mathrm{C}$

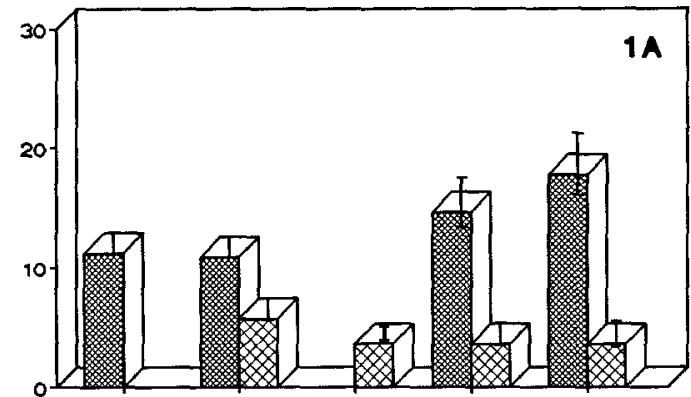

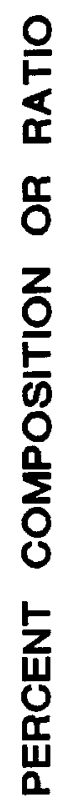
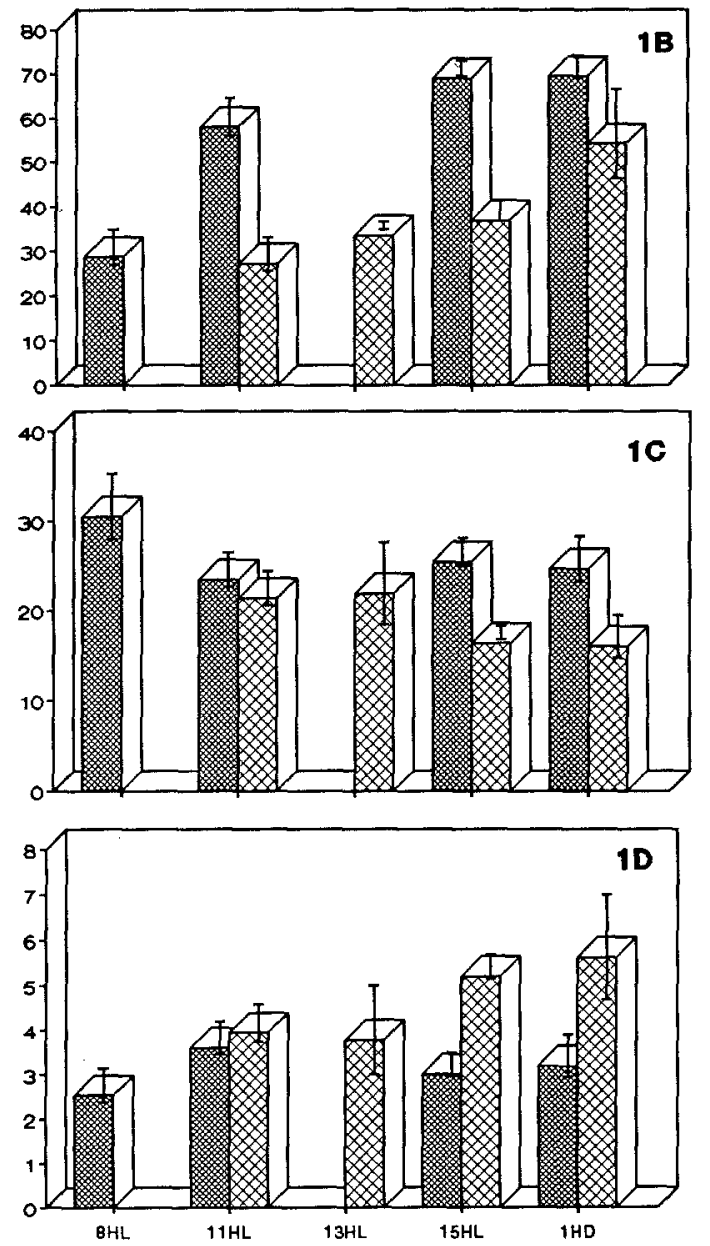

TIME IN LIGHT/DARK CYCLE

Fig. 1. Variation in selected control lipid classes and ratios as a function of time in light for Cyclotella meneghiniana. Data pooled from short and long term exposure experiments: A chlorophyll, \% composition; B triacylglycerol/free fatty acids, \% composition, $\mathbf{C}$ polar lipids $\%$ composition; D neutral/polar lipid ratio

\section{Changes in Lipid Classes During Exposure to 1,3,5-Trichlorobenzene}

Results of exposure experiments are presented in Figures 5-8. For ease of comparison, the percent change (exposed cells compared with control cultures) of the following three parame-
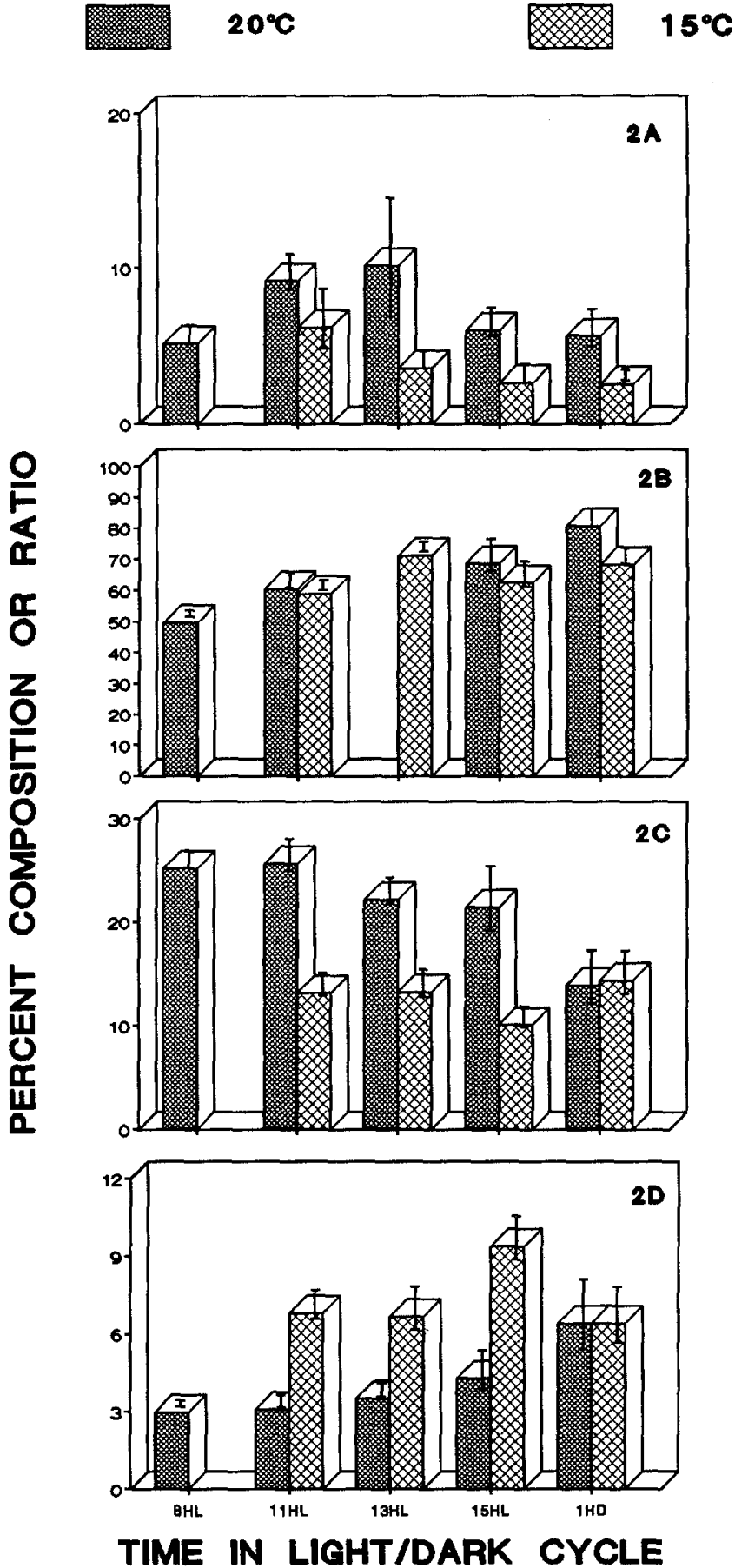

Fig. 2. Variation in selected control lipid classes and ratios as a function of time in light for Melosira varians. Data pooled from short and long term exposure experiments: A chlorophyll, \% composition; B triacylglycerol/free fatty acids, $\%$ composition; $\mathbf{C}$ polar lipids, $\%$ composition; D neutral/polar lipid ratio

ters have been graphed: Chlorophyll $a$, chlorophyll $a$ /neutral lipid ratio, and neutral/polar lipid ratio. Exposure of Cyclotella to the chlorinated benzene resulted in few significant changes in the cultures (Figure 5). It appears that within 24 hours after the exposure was initiated, there was a reduction in chlorophyll and an increase in neutral lipid in the 11 th hour exposure. However, 


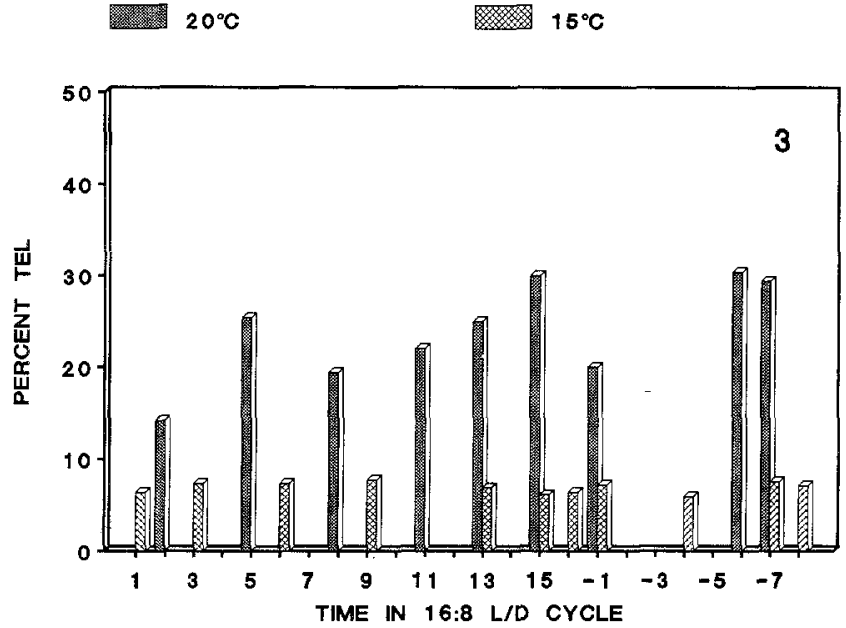

Fig. 3. Diel total extractable lipid (TEL) in Cyclotella meneghiniana as a function of hours in light. Negative numbers represent hours of dark.

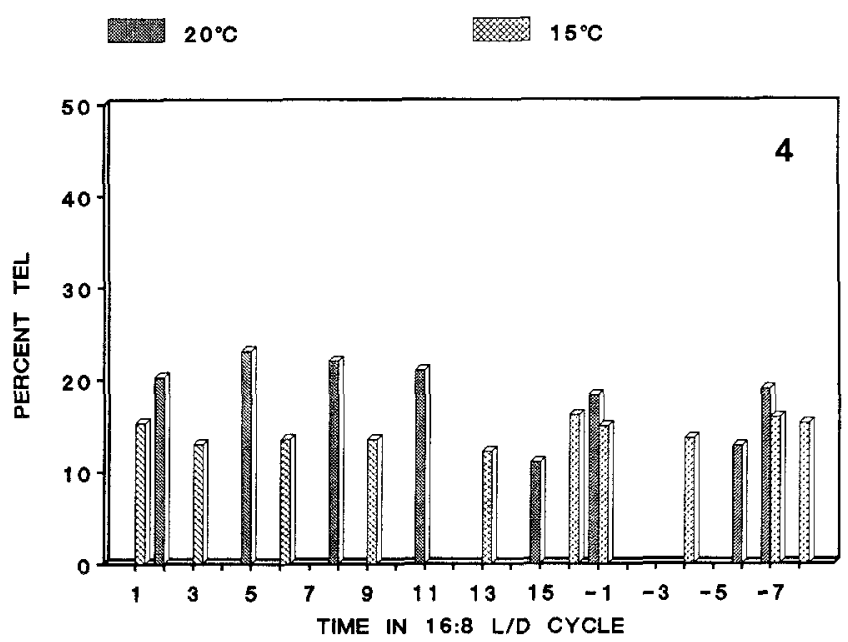

Fig. 4. Diel total extractable lipid (TEL) in Melosira varians as a function of hours in light. Negative numbers represent hours of dark.

there was recovery at $48 \mathrm{~h}$ and values approached those of control cultures. The variability observed is within the range of the standard errors of the numbers.

At $15^{\circ} \mathrm{C}$, there was an overall reduction in chlorophyll in cultures exposed to the chlorinated benzene. The reduction appeared to be more pronounced when the exposure was initiated in the 11 th hour of the light period (Figure 6). There was a general increase in the neutral/polar lipid ratio for both exposures (Figure 6).

The response of Melosira to the chlorinated benzene was quite different. Exposure in the 11th hour of the light period at $20^{\circ} \mathrm{C}$ resulted in approximately an $80 \%$ reduction in chlorophyll content (Figure 7). There was also a reduction in chlorophyll in the 15th hour exposure. However, the magnitude of the reduction was considerably less (Figure 7). During the 11th hour exposure, the neutral/polar lipid ratio was greater by a factor of $2-3$. In contrast, this ratio was reduced in the exposure initiated in the 15 th hour of the light period. At $15^{\circ} \mathrm{C}$, there was little variability in chlorophyll content or the neutral/polar lipid ratio
11TH HOUR

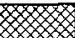

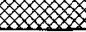

15 TH HOUR

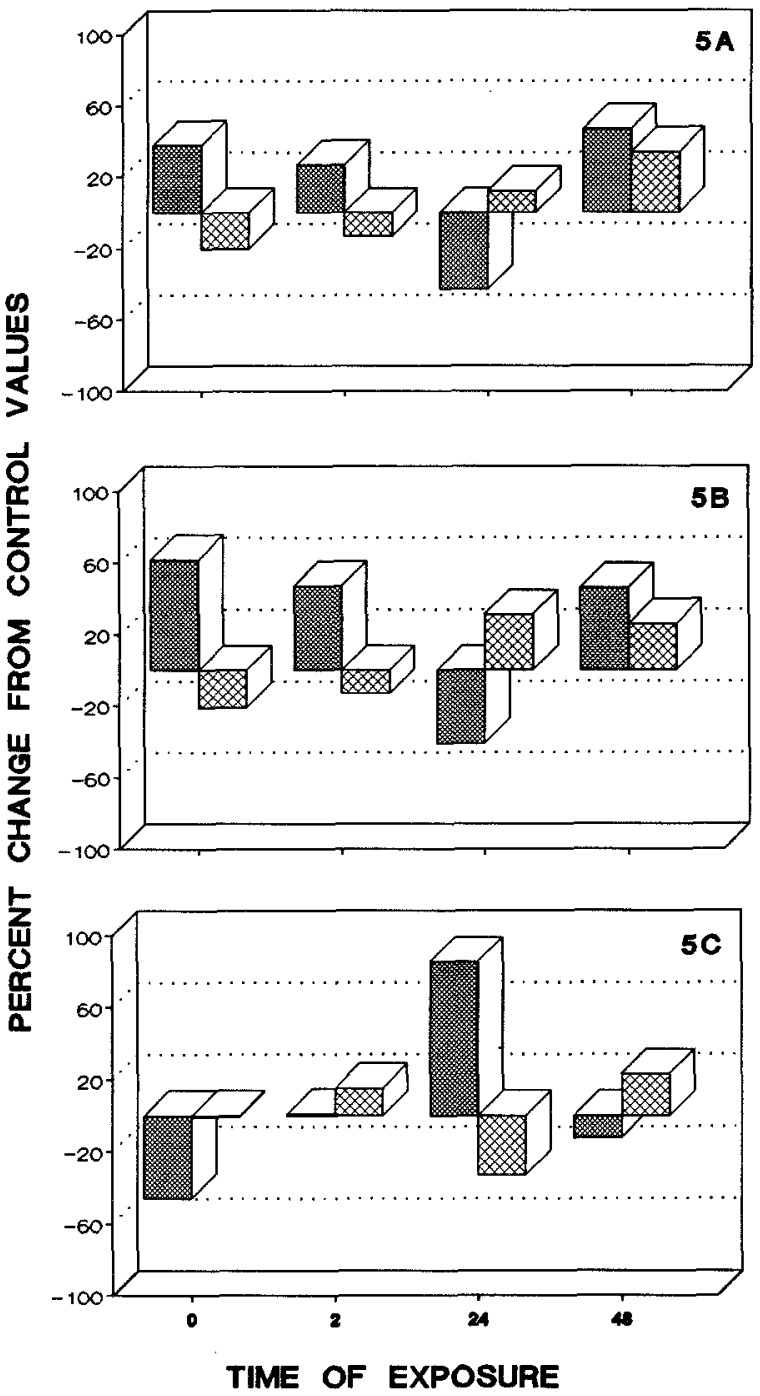

Fig. 5. Change in chlorophyll and lipid ratios as a function of exposure at $20^{\circ} \mathrm{C}$ for Cyclotella meneghiniana: A chlorophyll $a ; \mathbf{B}$ chlorophyll $a /$ Neutral lipids ratio; $\mathbf{C}$ neutral/polar lipids ratio.

(Figure 8). Changes in ratios were within the range of variability of the replicates.

\section{Discussion}

In general, lipophilic compounds having high octanol/water partition coefficients and low water solubilities tend to passively bioconcentrate. Accumulation of hydrophobic compounds appears to be related to lipid content (Canton et al. 1977; Clayton et al. 1977; Boyles 1980; Hutchinson et al. 1980). While lipid content may have an overall effect on bioaccumulation and food web transfer (indirect ecosystem effects), our results suggest that lipid class composition at the time of exposure may alter the short-term direct effects of the toxicant on individual phytoplankton taxa. 
11 TH HOUR

15 TH HOUR
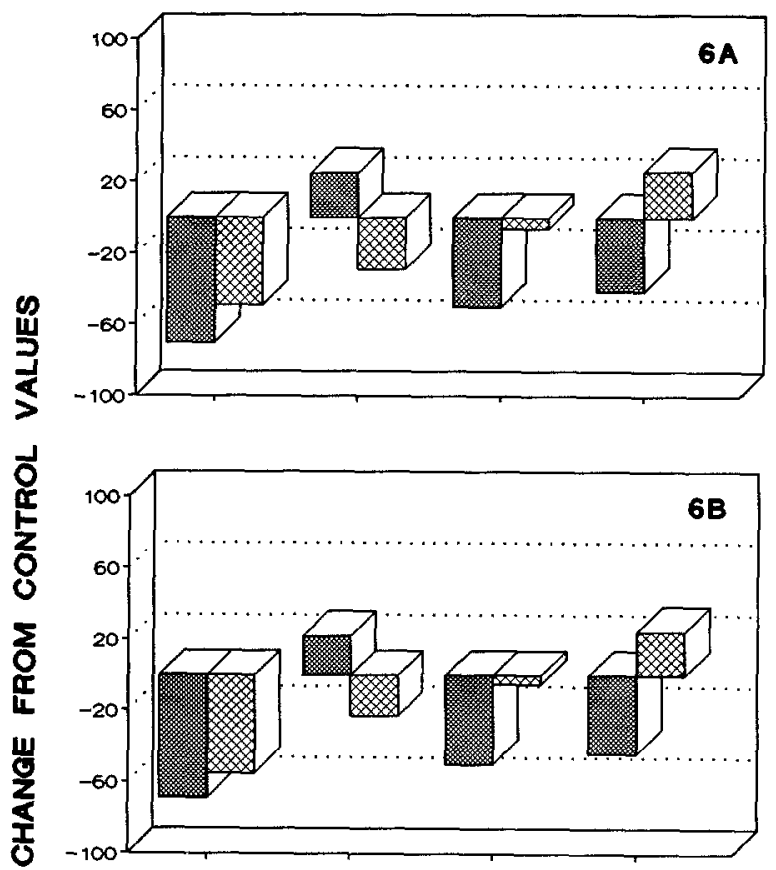

夏

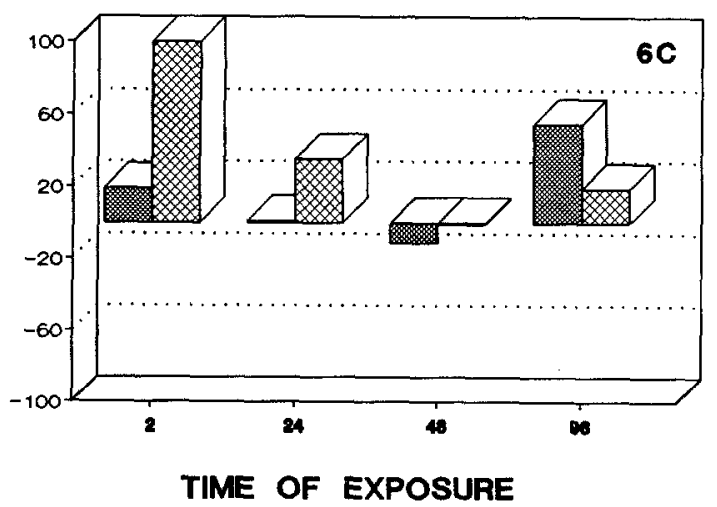

Fig. 6. Change in chlorophyll and lipid ratios as a function of exposure at $15^{\circ} \mathrm{C}$ for Cyclotella meneghiniana: A chlorophyll $a$; $\mathbf{B}$ chlorophyll $a /$ Neutral lipids ratio; $\mathbf{C}$ neutral/polar lipids ratio

Results presented here demonstrate that Melosira varians experienced more changes when exposed to 1,3,5-trichlorobenzene than Cyclotella meneghiniana. The small effects observed in Cyclotella are in agreement with previous studies which demonstrated that of the three trichlorobenzene isomers, the 1,3,5 isomer had the least effect (Sicko-Goad et al. 1989a1989d). These data might be explained in view of the physiological ecology of the organisms, diel total extractable lipid content, and lipid class composition patterns.

Cyclotella meneghiniana demonstrates a strong preference for long days (i.e., 20:4 h L/D) for optimal growth (Sicko-Goad and Andresen 1991). Growth occurs at $16: 8 \mathrm{~h} \mathrm{~L} / \mathrm{D}$, but it is not optimal. A reduction in temperature from $20^{\circ} \mathrm{C}$ to $15^{\circ} \mathrm{C}$ enhances growth at 16:8, and these more rapidly growing cells are characterized by a reduced average diel neutral/polar lipid ratio (Sicko-Goad and Andresen, unpublished observation), and a reduced triacylglycerol/polar lipid ratio.
11 TH HOUR

15TH HOUR

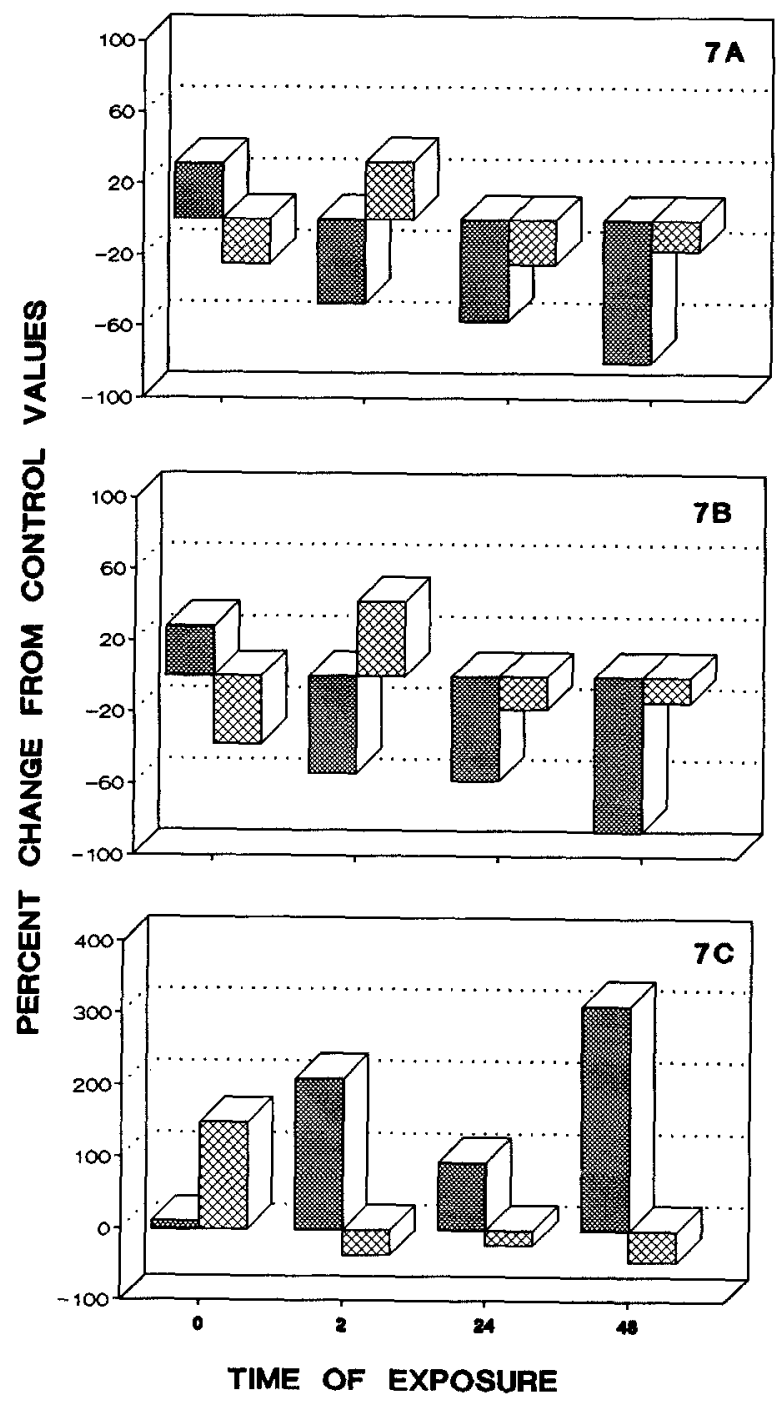

Fig. 7. Change in chlorophyll and lipid ratios as a function of exposure at $20^{\circ} \mathrm{C}$ for Melosira varians: A chlorophyll $a$; $\mathbf{B}$ chlorophyll $a /$ Neutral lipids ratio; $\mathbf{C}$ neutral/polar lipids ratio

Melosira varians, on the other hand, is able to tolerate a wide variety of light regimes $(12: 12,16: 8,20: 4 \mathrm{~h} \mathrm{~L} / \mathrm{D})$, although growth is somewhat more rapid and sustained for longer periods of time under a 12:12 h L/D regime. Lipid class analyses under a variety of light regimes suggests that of the two light and temperature regimes utilized in this experiment, the $16: 8 \mathrm{~h}$ regime at $20^{\circ} \mathrm{C}$ results in higher average diel concentrations of chlorophyll $a$ and polar lipids. Since more effects occurred in Cyclotella at $15^{\circ} \mathrm{C}$ and in Melosira at $20^{\circ} \mathrm{C}$, it is apparent that more rapidly growing cells are more susceptible to short term effects of lipophilic toxicants.

The results of this experiment and our previous experiments with Cyclotella (Sicko-Goad et al. 1989a-d) may best be explained in terms of the ratio of triacylglycerol to polar lipids. For the four previous exposure experiments, we found exposure to both 1,2,3- and 1,3,5-trichlorobenzene resulted in significant changes in fatty acid composition and morphological com- 


\section{$11 \mathrm{TH}$ HOUR}

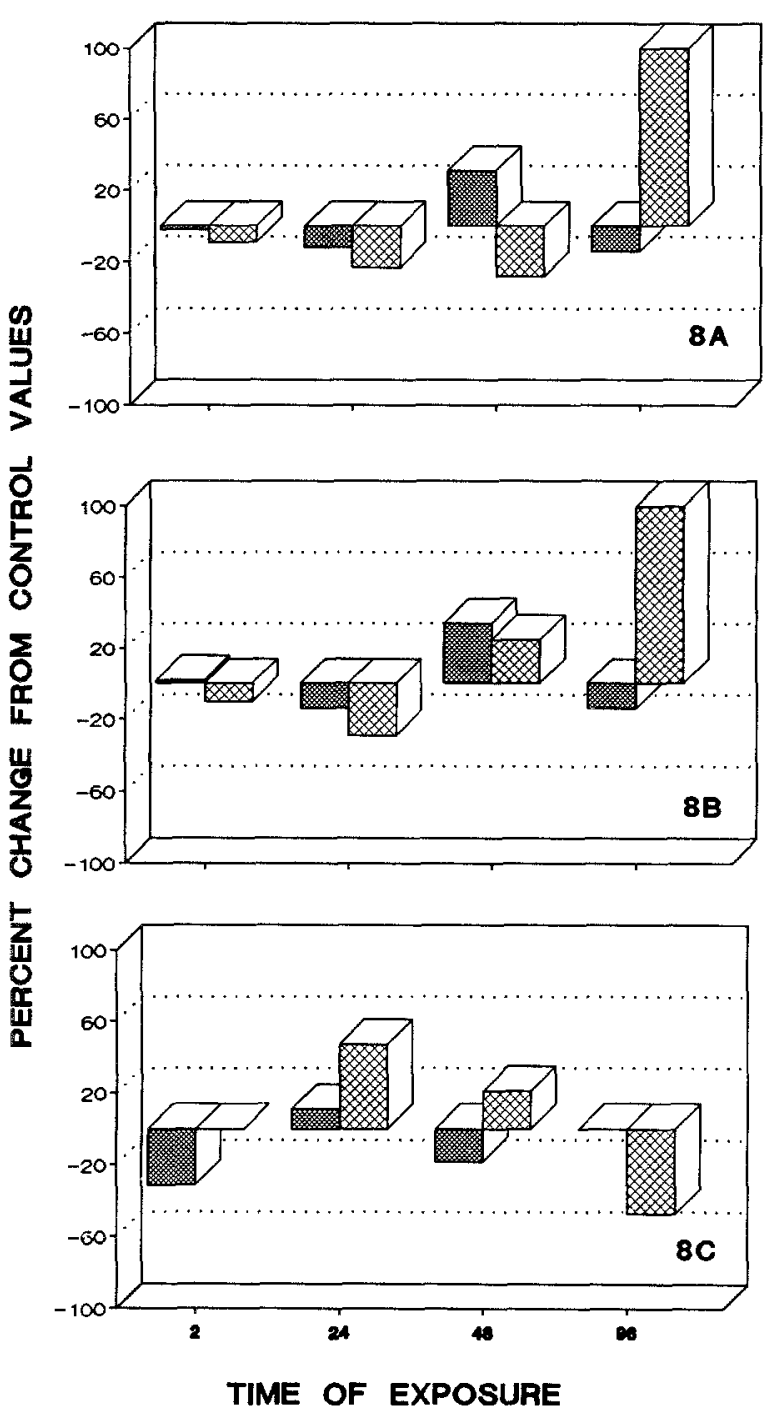

Fig. 8. Change in chlorophyll and lipid ratios as a function of exposure at $15^{\circ} \mathrm{C}$ for Melosira varians: A chlorophyll $a ;$ B chlorophyll a/Neutral lipids ratio; $\mathbf{C}$ neutral/polar lipids ratio

partments early in the sampling scheme. That is, most changes occurred within the first $24 \mathrm{~h}$ of exposure. Both of these experiments were initiated between the 6th and 7th hours of the light period, when triacylglycerol is low and polar lipids are high. Experiments with 1,2,4-trichlorobenzene and pentachlorobenzene were initiated between the 10th and 11th hours of light period, when triacylglycerols are approximately doubled in the cells. Effects of the latter compounds were observed in greater numbers in later sampling times ( 5 days). In the present experiment, changes were observed in lipid class composition (i.e. increase in triacylglycerols, reduction in chlorophyll, increase in the neutral/polar lipid ratio) when the exposure was initiated in the 11 th hour of the light cycle at $20^{\circ} \mathrm{C}$ and in both exposures at $15^{\circ} \mathrm{C}$. Cultures grown under these conditions generally have a lower concentration of triacylglycerols and lower ratios of $\mathrm{TG} /$ polar lipids when compared with samples taken in the 15 th hour of light. Although some changes were observed, 1,3,5- trichlorobenzene in concentrations near that of water solubility does not have much overall effect on Cyclotella meneghiniana.

The pattern of effect appears to be somewhat similar, though more pronounced in Melosira varians, where short term effects were observed in the 11 th hour exposure at $20^{\circ} \mathrm{C}$. Diel lipid class composition patterns of the two diatoms show remarkable similarities. Although in Melosira chlorophyll concentration is higher in the 11th hour than in the 15th hour, both diatoms experience increases in chlorophyll concentration at the time exposure was initiated. For Melosira, the increase is observed between the 11th and 13th hours of the light period, whereas in Cyclotella, increases are observed between the 11 th and 15th hours. Triacylglycerol is also lower in Melosira in the 11th hour of the light period. Polar lipids are at their maximum at this time, and the neutral/polar lipid ratio rises steadily in the latter part of the light period. Consequently, it appears that at least some short term effects of 1,3,5-trichlorobenzene are more pronounced when exposure occurs when chlorophyll synthesis is occurring, polar lipids are generally higher, and the ratio of triacylglycerol to polar lipid is reduced.

Relatively little is known about photoperiodic changes in lipid content and composition in phytoplankton. Shifrin and Chisholm (1981) demonstrated that changes in total lipids over a diel cycle were directly related to cell growth and reproduction. Similarly, Rivkin (1985) reported diatoms utilize lipids and low molecular weight polymers for respiration and/or protein synthesis at night. In a more recent study, Sukenik and Carmeli (1991) demonstrated that in a Eustigmatophycean alga, Nannochloropsis, neutral lipids such as triacylglycerol were synthesized and accumulated in the light period and rapidly turned over in the dark. These authors demonstrated that on a 12:12 h L/D cycle, triacyglycerols increased more than threefold in a period of six hours preceding the onset of the dark period. These studies demonstrate that large variations in lipid content and composition occur as part of a natural diel cycle in a wide variety of phytoplankton taxa.

The short-term changes that occurred in Cyclotella were minor and some recovery was evident at 48 hours. Rapid recovery from short-term or sublethal toxicant doses is not uncommon (Soto et al. 1977; Sandmann and Boger 1980; Sicko-Goad 1982; Hardy et al. 1985). Cyclotella may also be less susceptible to 1,3,5-trichlorobenzene than Melosira because it extrudes chitin strands through the frustule. These chitin strands have at least one function of providing buoyancy for the cells (Smucker 1991) and may provide additional surface area for the adsorption of toxicants effectively reducing the concentration available to the cell. In addition to chitin strands, $C$. meneghiniana has been observed to produce copious mucilage during growth in culture (Sicko-Goad and Andresen unpublished observation). In the majority of the algae the role of mucilage is poorly documented, however speculations as to its varied roles abound (Boney 1981).

It has been suggested many times that environmental variables and physiological status of cells may play an important role in toxicity studies (Fisher et al. 1976; Conner and Mahanty 1979; Karydis and Fogg 1980; Sicko-Goad and Lazinsky 1986; Neumann et al. 1987). Our studies suggest that in addition to these factors, simple diel variations in metabolic patterns may also affect the outcome of toxicity studies. Extreme care should be taken in comparative toxicity bioassays of lipophilic compounds so that assays are always initiated at the same time of day to ensure uniform lipid content and composition. 
Acknowledgments. Supported by Grants 88-0315 from the Air Force Office of Scientific Research and R-814194 from the Office of Exploratory Research, U.S. Environmental Protection Agency. M. B. Edlund provided technical support. Contribution No. 552 of the Center for Great Lakes and Aquatic Sciences.

\section{References}

Boney AD (1981) Mucilage: the ubiquitous algal attribute. Br Phycol J 16:115-132

Boyles DT (1980) Toxicity of hydrocarbons and their halogenated derivatives in an aqueous environment. In: Afghan BK, Mackay D (eds), Hydrocarbons and halogenated hydrocarbons in the aquatic environment. Plenum Press, NY, pp 545-557

Canton JH, Van Esch GJ, Greve PA, van Hellemond ABAM (1977) Accumulation and elimination of $\alpha$-hexachlorocyclohexane (HCH) by the marine algae Chlamydomonas and Dunaliella. Water Res 11:111-115

Clayton JR, Pavlou SP, Breitner NF (1977) Polychlorinated biphenyls in coastal marine zooplankton: bioaccumulation by equilibrium partitioning. Environ Sci Technol 11:676-682

Conner AJ, Mahanty HK (1979) Growth responses of unicellular algae to polychlorinated biphenyls: new evidence for photosynthetic inhibition. Mauri Ora 7:3-17

Fisher NS, Guillard RRL, Wurster CF (1976) Effects of a chlorinated hydrocarbon pollutant on the growth kinetics of a marine diatom. In: Canala RP (ed) Modeling biochemical processes in aquatic ecosystems. Ann Arbor Science, Ann Arbor, MI, pp 305-317

Guillard RRL (1975) Culture of phytoplankton for feeding marine invertebrates. In: Smith WL, Chanley MH (eds) Culture of marine invertebrate animals. Plenum Press, NY, pp 39-59

Hardy JT, Dauble DD, Felice LJ (1985) Aquatic fate of synfuel residues: bioaccumulation of aniline and phenol by the freshwater phytoplankton Scendesmus quadricauda. Environ Toxicol Chem 4:29-35

Hutchinson TA, Hellebust JA, Tam D, Mackay D, Mascarenhas RA, Shiu WY (1980) The correlation of the toxicity to algae of hydrocarbons and halogenated hydrocarbons with their physical-chemical properties. In: Afghan BK, Mackay D (eds), Hydrocarbons and halogenated hydrocarbons in the aquatic environment. Plenum, NY, pp 577-586

Karydis M, Fogg GE (1980) Physiological effects of hydrocarbons on the marine diatom, Cyclotella cryptica. Microb Ecol 6:281-290

Neumann W, Laasch H, Urbach W (1987) Mechanisms of herbicide sorption in microalgae and the influence of environmental factors. Pest Biochem Physiol 27:189-200

Orcutt DM, and Patterson GW (1975) Sterol, fatty acid, and elemental composition of diatoms grown in chemically defined media. Comp Biochem Physiol 50B:579-583

Parrish CC (1986) Dissolved and particulate lipid classes in the aquatic environment. $\mathrm{PhD}$ thesis, Dalhousic University, Halifax, Nova Scotia, Canada, 259 pp
Parrish CC, Ackman RG (1985) Calibration of the Iatroscan-Chromarod System for marine lipid class analysis. Lipids 20:521-530

Rivkin RB (1985) Carbon-14 labelling pattern of individual marine phytoplankton from natural populations. Mar Biol 89:135-142

Sandmann G, Boger P (1980) Copper deficiency and toxicity in Scenedesmus. Z Pflanzenphysiol 98:53-59

Shifrin NS, Chisholm SW (1981) Phytoplankton lipids: interspecific differences and effects of nitrate, silicate, and light-dark cycles. J Phycol 17:374-384

Sicko-Goad L (1982) A morphometric analysis of algal response to low-dose, short-term heavy metal exposure. Protoplasma 110:75-86

Sicko-Goad L, Andresen NA (1991) Effect of growth and light/dark cycles on diatom lipid content and composition. J Phycol 27:710718

Sicko-Goad L, Lazinsky D (1986) Quantitative ultrastructural changes associated with lead-coupled luxury phosphate uptake and polyphosphate utilization. Arch Environ Contam Toxicol 15:617-627

Sicko-Goad L, Evans MS, Lazinsky D, Hall J, Simmons MS (1989a) Effects of chlorinated benzenes on diatom fatty acid composition and quantitative morphology. IV. Pentachlorobenzene and comparison with trichlorobenzene isomers. Arch Environ Contam Toxicol 18:656-668

Sicko-Goad L, Hall J, Lazinsky D, Simmons MS (1989b) Effects of chlorinated benzenes on diatom fatty acid composition and quantitative morphology. Il. 1,3,5-Trichlorobenzene. Arch Environ Contam Toxicol 18:638-646

_ $~-\ldots, \ldots, \ldots,(1989 \mathrm{c})$ Effects of chlorinated benzenes on diatom fatty acid composition and quantitative morphology. III. 1,2,3-trichlorobenzene. Arch Environ Contam Toxicol 18:647-655

Sicko-Goad L, Lazinsky D, Hall J, Simmons MS (1989d) Effects of chlorinated benzenes on diatom fatty acid composition and quantitative morphology. I. 1,2,4-Trichlorobenzene. Arch Environ Contam Toxicol 18:629-637

Sicko-Goad L, Simmons MS, Lazinsky D, Hall J (1988) Effect of light cycle on diatom fatty acid composition and quantitative morphology. J Phycol 24:1-7

Smucker RA (1991) Chitin primary production. Biochem System Ecol 19:357-369

Soto C, Hellebust JA, Hutchinson TC (1977) Effect of naphthalene and aqueous crude oil extracts on the green flagellate Chlamydomonas angulosa. III. Changes in cellular compostion. Can J Bot $55: 2765-2777$

Sukenik A, Carmeli Y (1990) Lipid synthesis and fatty acid composition in Nannochloropsis sp. (Eustigmatophyceae) grown in a lightdark cycle. J Phycol 26:463-469

Manuscript received May 19, 1992 and in revised form September 26, 1992 